
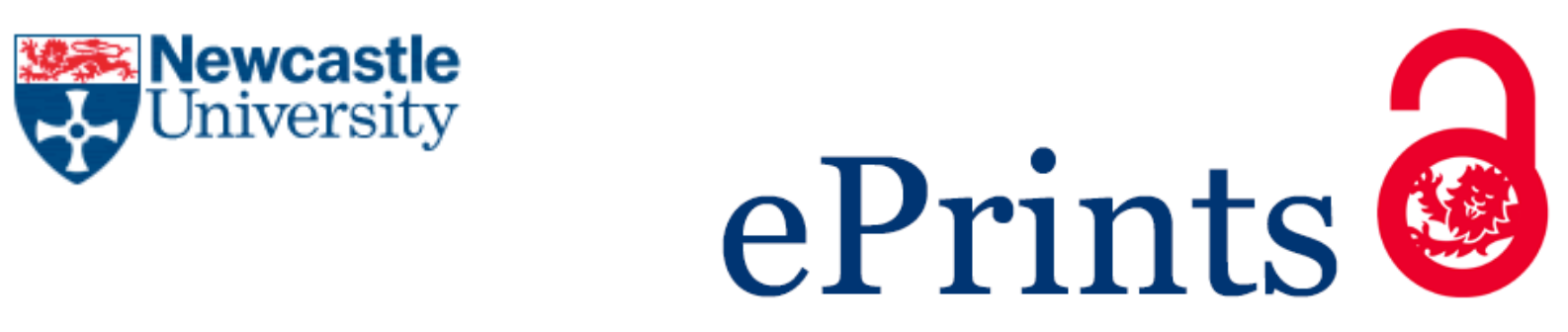

Gafijczuk D.

Vividness, time, and the restitution of sociological imagination.

The Sociological Review 2016

DOI: http://dx.doi.org/10.1111/1467-954X.12419

\title{
Copyright:
}

This is the peer reviewed version of the following article: Gafijczuk D. Vividness, time, and the restitution of sociological imagination. The Sociological Review 2016, which has been published in final form at http://dx.doi.org/10.1111/1467-954X.12419. This article may be used for non-commercial purposes in accordance with Wiley Terms and Conditions for Self-Archiving.

DOI link to article:

http://dx.doi.org/10.1111/1467-954X.12419

Date deposited:

$16 / 09 / 2016$

Embargo release date:

17 October 2017 


\section{Vividness, Time, and the Restitution of Sociological Imagination}

The past is never dead. It's not even past - William Faulkner

... was knocks again and again at the door of the is - Sigizmund Krzhizhanovsky

[Forthcoming in The Sociological Review. Final accepted version July 1, 2016. Deposited in Newcastle University Depository for Public Access September 16, 2016]

Author: Dr Dariusz Gafijczuk (Newcastle University, Sociology)

Sociological practice that confines its inquiry to 'the static knife-edge moments' of extremely short duration, as C. Wright Mills described them more than five decades ago, (2000 [1959]: 224) is caught in the 'sticky' present' (Uprichard, 2012). Vibrating to the rhythm and the pulse of the moment, it falls into a 'perceptive complicity' with it. The fact that for Mills as well as the classical tradition, sociological imagination with no time for temporality was, in essence, unimaginable, deserves more consideration than it has received. Notwithstanding the few recent attempts to reinsert historical sensibility into the sociological research apparatus, such as David Inglis's call for 'a profoundly historicallysensitive sociology' (2014: 114), William Sewell's arguments for an 'eventful temporality' that is 'radically foreign to normal sociological thinking' (2005: 83) or Barbara Adam's (1990, 1995) well known engagement with time as indispensable to social thought, the contemporary sociological imagination has proven remarkably resistant to duration as an active analytical dimension. It is this imagination starved of temporal sensibility, in this case the feeling for the past, that I would like to confront. The aim of this confrontation is to reflect more systematically on the project of renovation that sociology must undergo in order to remain relevant, by which I mean, a responsive not merely a reactive social 
science. The call for this type of renovation, or even more accurately restitution of an imagination that, among other things, is able to work with time, has recently come through the notion of live sociology (Back and Puwar, 2012).' The task of live, as opposed to a dead social science based on 'zombie concepts' and 'fossil facts' (Back 2012: 21) is to generate new forms of attentiveness by extending our sensory arrangements in new and unpredictable ways. Thus, 'the first principle of live sociology' according to Back is to pay 'attention to how a wider range of the senses changes the quality of data and makes other kinds of critical imagination possible' (2012: 29). This also means paying attention to time and the multiple shapes duration assumes when enacted as a lived moment, thus avoiding the 'trap of the now; of being caught in the newest and the most recent nets of 'a relatively small time horizon' (Back and Puwar, 2012: 8).

Indeed, the project of inventing and then continuously remaking sociological practice to match the new intensity of life, in itself the founding moment of the sociological approach, cannot proceed without also finding a way 'to inject time and temporality routinely and mundanely into our social research practices' (Uprichard, 2012: 135). Is there a way, habitually and systematically, to inject temporality into our analytical frameworks? This is the question at hand, and I will propose a model of how this injection of time, or at least a segment of it in the form of reactivated past, can be accomplished. My aim is to engage in a more systematic demonstration of how such analytically reactivated past $^{2}$ generates types of attentiveness that can provide fresh access to the complexities of current life - still the ultimate analytical goal, given sociology's unique domain as the science of the contemporary. There is a long-standing technique that shows a lot of promise and provides guidance on how such reactivated past can be triggered and used analytically - what in antiquity and throughout the early modern period was known as 
enargeia (vividness); a special type of imagination that persistently and intensely worked with the past, using it as a type of 'live optics' for the present. This type of approach strikes at the core of live sociology, intensifying the element that constitutes the 'social life' of its method, marked by 'the changing historical boundaries between the implicit and the explicit...' (Savage, 2013: 18). This relationship between the implicit and the explicit, most directly visible in how the past is put to use, will be a recurring theme in our discussion. Such 'thinking with the past' must go further than the traditional route of historical sociology, even when the latter is made into 'the essence of the discipline' as Philip Abrams (1982: 2) understood it. It is not enough to rehash old timelines, describe transitions between state formations, study revolutions as the indisputable markers of modernity. The reason for this is simple: we have outgrown the standard, bounded, circumscribed and delimited collective identities and their histories. ${ }^{3}$ Taking-stock of historical sociology's position today, Elizabeth Clemens is unequivocal on this point:

The most striking shift [in historical sociology] is from the imagery of systems and crisis, which highlighted revolution and state-building, to multi-dimensional understandings of emergence and destabilization (2007: 529).

This sense of emergent, destabilized and unbounded identity has also infiltrated historical memory, which is in danger of collapsing under the weight of more and more recent past impinging upon the present. Indeed, 'the past has become part of the present in ways simply unimaginable in earlier centuries (Huyssen, 2003: 1) - although perhaps not completely, as my argument about enargeia will show. It is fair to say that contemporary Sociology has mostly ignored this new and growing in intensity temporal environment that makes the boundary between the past and the present increasingly permeable. 
We are thus in need of a sociological imagination that can take a 'tiger's leap into the past', as Walter Benjamin (Benjamin, 1968: 261)) already observed in the early decades of the last century - an analytic approach that mimics what has been happening on the everyday level of mass culture and politics. Today, such culturally active past has become a ubiquitous phenomenon, especially visible through the boom in memory culture of museums, heritage commemorations, truth-commissions in charge of redressing past atrocities and trauma, to retro movements in fashion, music, repro-furniture, and the 'massmarking of nostalgia' (Huyssen, 2003: 14). ${ }^{4}$ Only an imagination able to actively bring the past into contact with the present can trigger a mode of observation with the power to meaningfully enliven the analytically stunted (given its immediacy) moment. This is not to say that there is no place for the more standard and still valuable engagement with history or the sociological present. But in order to remain in touch with the contemporary complexity of life which has been particularly intense on the temporal plane, sociology must also find a new approach to how we deal with and use time as an analytical asset that can match how duration is lived and manipulated.

Thus, the unfolding discussion explores the relationship between sociological imagination and temporality with whose help we might begin to define analytical frames 'equal to the new coordinated forms of social reality manifest in the contemporary social world' (Back and Puwar, 2012: 7; see also Adkins and Lury, 2009). This attempt to enliven sociological inquiry 'involves immersion in time' because only time has the ability to trigger ‘unpredictable attentiveness' (Back and Puwar, 2012: 13) necessary for a continually retuned and sharpened analytical perception. This is a space soaked through with temporality where, to quote Mills in full 
an Indian Brahmin of the 1850 stands alongside a pioneer farmer of Illinois; an eighteenth century English Gentleman alongside an Australian aboriginal, together with a Chinese peasant of one hundred years ago, a politician in Bolivia today, a feudal knight of France, and English suffragette on hunger strike in 1914, a Hollywood starlet, a Roman patrician. To write of 'man' is to write of all these men and women - also of Goethe, and of the girl next door. (Mills, 2000 [1959]: 133)

It is only this kind of radical imagination (and Mills knew of nor argued for any other), seeking out relationships as much as taking what the world has on offer, smashing together the seemingly unrelated facts, events, and biographies like in a particle accelerator while paying 'explicit attention to much more than 'the facts" (Mills, 2000 [1959]: 145) that can create a propitious analytical environment where new forms of relevance and understanding could take hold.

\section{Restitution of the Past}

The sense of urgency to renew sociology's analytical prowess, most recently expressed as 'the crisis of method' (Savage \& Burrows, 2007, 2009) is in part the symptom of a new temporal regime. Supported by the so-called 'big data' - the seemingly boundless and incessantly growing body of 'real time' information that, just as quickly, is saved, stored, and in essence, 'historicized' - this type of temporal reality creates what Nietzsche in the second of his Untimely Meditations (1997 [1873] diagnosed as a 'sleepless' present. Overwhelmed by history as a type of forevermore extended archive, it is a present that loses the ability to forget (1997 [1873]: 62). Two examples of this kind of logic in operation today, which I will only mention and just as quickly leave aside as they would take us too far afield, are (to date the still unsuccessful) project to create a living Twitter archive 'housed' at the Library of Congress, a searchable database of some half a trillion (and growing) tweets ${ }^{5}$; and the recent decision against Google by the European Court of Justice, literally legislating the 'Right to 
be Forgotten', although given how the digital trace is virtually non-erasable, the directive is more about making invisible, rather than forgetting as such. ${ }^{6}$ These two instances are but a mere symptom of the contemporary, intensified temporal space, where each 'moment thas the potential tol become the monument' to its presence, a logic most visibly on display in the many 'retro' phenomena, from vintage clothing, furniture, and technology, to pop music's market for revivalist sound (Reynolds, 2011).

Whether or not sociology is in a state of crisis today is debatable, especially if we simply understand crisis in an alarmist sense, as a state of emergency triggered by the sudden seizure in the effectiveness of traditional methodologies. But it is difficult to deny that there is a sense of urgency which spills over form the new temporal regimes that make things appear in specific and unprecedented configurations. Any new sense of the contemporary social environment that hopes to match the currency of life must also come to grips with this condition of a sleepless/restless present, which has in fact grown up together with modernity. Its latest reincarnation in a digital form of live data streams and instantaneous archives merely intensifies its basic, hyper-temporal, profile. This kind of thinking goes hand in hand with being responsive to contemporary upheavals and its myriad of pressures, perhaps even crises, as long as these are understood in the specific historical sense as something that 'takes hold of old experiences and transforms them metaphorically in ways that create altogether new expectations' (Koselleck, 2006: 374), mobilizing temporality in new ways. In this form, crisis is very much the 'structural signature of modernity' (Koselleck, 2006: 372) with a mostly untapped analytical potential.

The past as actively reconstituted in the present, the one that in our own way we have been rediscovering in the first decade and a half of this century is different from the standard historical past, taken to be the well-defined and distinct precursor to the present.' 
Indeed, it is hard to deny that the first decade of our century has been characterized by 'rampant recycling [where the] bygone genres [were] revived and renovated, vintage sonic material reprocessed and recombined' (Reynolds, 2011: xi) creating an intriguing return to a much older sense of duration. One telling example of this sense of time based on the practice of re-use and recycling applied to various artifacts from the past, including entire urban centers, is the Eternal City of Rome (as it was known) and its ruins. Well into the nineteenth century, the past and its 'antiquities were resources for Rome, in all sense of the term: it lived off them and on them' (Hartog, 2015: 166). ${ }^{8}$ From the historical standpoint that takes age as the supreme value in itself and treats Rome's ancient ruins (now protected under the UNESCO World Heritage Site legislation) as the founding space of Western identity, the city was close to a tragic and unforgivable disappearance. It is only the overdeveloped sense of what Nietzsche called antiquarian history (1997 [1873]) that is responsible for naturalizing the past as a space of conservation and fragile materiality in need of protection, instead of a past as a living resource for the present. And it is this older notion of the past used as raw-material for the present, something that we live on the biographical and everyday levels - a past that makes new things from old components and a type of representation with the power to make the relics of the past into evercontemporary objects' (Hartog, 2015: 154), that also speaks to the process of 'liveliness' as a mode of inquiry. ${ }^{9}$ This is especially so, because this type of continually reconstituted past has become something like an environmental signature of the contemporary condition. Hence, in a similar manner to Paul Rabinow's definition, I understand this contemporary condition of restless fabrication of data and information as a space overflowing with the old cultural, social, and political formations that interact concurrently while 'moving through recent past towards near future in a non-linear iteration' (2008: 2). We are speaking here 
about the interminable emergence of phenomena whipped up by the renewable resourcefulness and interplay of communication (in the broadest possible sense) constantly spun around its axis by past definitions, present embodiments, and contingent futures.

\section{Reactivated Past - Vivid Present}

All this begs the question: How can we become incisive and accurate witnesses to contemporary life in all its textures? By finding a way of working with the past, engaging it as a lively dimension of our presence in the contemporary setting - that, in addition to other, concurrently active analytical frames. Witnessing, in any case, is not simply a passive sensory playback of what was once observed but always an active reconstruction of an event. History, in its initial rendition via Herodotus and Thucydides, was a type of reportage on current or quite recent events, frequently collected through intermediaries and informants. ${ }^{10}$ As such, the ancient historian aimed to turn the audience of listeners or readers into virtual observers of proximate but, in one form or another, already inaccessible phenomena. Occurrences that could not be experienced as such but still fell within the orbit of the commonly shared worldview could only be recovered by more or less intense acts of approximation. This kind of approach does not describe or narrate the past so much as it creates a series of simulated encounters with it. Yes, it is a space, or a mode of inquiry 'replete with real things and processes but directed, removed from habitual courses' (Rabinow, 2008: 50) - a special temporal orientation that repatriates the past and its flavour, as much as this is possible, into the present. Only this kind of approach can revitalize our observational practices, giving us a new sense of meaning and relevance of the contemporary world. And we do not even have to invent anything new here, just 
readapt. One way this kind of process had been put into practice and the one I would like to recover is the ancient technique of enargeia - vividness.

In most general terms 'the enargeia or evidentia of the description ... aims to generate effective images which depict as present that which is temporally and spatially absent' (Plett, 2012: 12). Rendered as clarity, vividness, palpability, and evidence, enargeia is not to be confused with the still surviving, and parallel concept of energeia - signifying action, activity, and energy. If the past is always mediated, enargeia, harking back to the Greek tradition, was a rhetorical and literary device that attempted to bring the past as near as possible into the present. In this sense, enargeia constructed an adjacent dimension to the ungraspable immediacy of things - a space in which the remnants of prior life could be amplified, giving one the sense of the, technically speaking, missing reality. In this type of model, the past was not 'discovered' as it later became thanks to both the ecclesiastical and antiquarian traditions of history, with the former searching for authentic origins and the latter using various artifacts in support of that search (Ginsburg, 2012) but re-enacted through live rendering. In Latin, enargeia took on the more familiar form of demonstration (demonstratio), illustration (illustratio) and evidence (evidentia), continuing the tradition of making the sense of sight the primary channel of observation. When the Roman scholar Quntilian (35 - 100 AD) referred to Cicero's translation and interpretation of enargeia he emphasized the interplay between illumination and actuality: 'illumination and actuality, which makes us seem not so much to narrate as to exhibit the actual scene, while our emotions will be no less actively stirred than if we were present at the actual occurrence' (in Ginsburg, 2012: 9). Thus, the most interesting and from the standpoint of our argument crucial usage of enargeia is given by its enlivening effect, as the vehicle for the arousal of the listener/spectator who then virtually becomes a witness, or more accurately a virtual witness, 
to the depicted scene, literary, poetic, or in fact, historical. For instance, according to Dionysius of Halicarnassus (ca. 50 B.C. - 7 A.D.), enargeia is the stylistic effect in which appeal is made to the senses of the listener and the attendant circumstances are described in such a way that the listener will be turned into an eyewitness' (in Zanker, 1981: 297). In a similar fashion, Thomas Hobbes (1588-1679) reflecting on Thucydides, observed that the ancient historian wanted

[t]o make his auditor a spectator, and to cast his reader into the same passions that they were in that were beholders. [These things] are so described and so evidently set before our eyes that the mind of the reader is no less affected therewith than if he had been present in the actions (in Plett, 2012: 11).

Crucially, enargeia 'brings about a time shift, in that something from the past or future is made present and, as it were, visibly exhibited' (Plett, 2012: 8).

It is in this sense that enargeia, in its various renderings ${ }^{11}$ becomes what we might call a total phenomenon of perception and not simply a mode of representation (Sharpling, 2002: 174). Over time, especially during the Renaissance, in the hands of one of its most famous representatives Desiderius Erasmus of Rotterdam (1466 - 1536), enargeia migrated from the oral tradition, to the art of effective, powerful, and striking writing based on abundance and variation of expression, and the 'liveliness' of words (copia). It became a technique of amplification across four crucial dimensions of presence - of persons (prosopoeia/prosopographia), things (hypotyposis), spaces (topographia), and temporalities (chronographia). All four are crucial to the 'fully embodied' description of a phenomenon we might want to engage analytically.

Long before Saussure and the sliding signifiers of the post-modernists, already in 1511 Erasmus clearly perceived the arbitrary relationship between words and things, thus sketching the outlines of the communicative environment we still share. ${ }^{12}$ This early- 
modern realization that language also shapes and not merely reflects or resembles the world, enabled the use of words methodologically - as tools to be applied to the unwieldy reality. Enargeia was part of that tool box. It took what was simply a description and enlarged or more accurately amplified its range which, not unlike the recent arguments for 'paying attention to the social within a wider range of senses (Back and Puwar, 2012: 15) enabled one to 'evoke a wide range of sense impressions' (Sharpling, 2002: 175). Based on this notion, language became an 'evocative replica of living experience' (Sharpling, 2002: 188). Enargeia, according to Erasmus, is one of eleven methods of rhetorical amplification presented, even though arguably the most significant one because using it 'we do not state a thing simply, but set it forth to be viewed as though portrayed in colour on a tablet, so that it may seem that we have painted, not narrated, and that the reader has seen not read' (Erasmus, 2012 [1513]: 47). As such, the technique of enargeia becomes the closest possible surrogate to immediate vision (autopsia) allowing us to 'see' and feel phenomena that, technically speaking, are outside the range of our senses. It is precisely in this way, recalling our earlier discussion, that enargeia became the prime technique for making the implicit explicit.

Important to note here is that this kind of sensory complex built around language, image, and temporal morphology, is not to be equated simply with the effect of a 'true to life' pictorial representation. Quite the opposite: 'Enargeia differs from pictorial verisimilitude in the complexity of the receptive act it demands from the spectator' (Leach, 1988: 7). Such demand is not simply lodged in the quality of the text or speech, but in the aggregate image that arises when the loop of sensory stimulation, from text/orator to reader/spectator is completed, which operates in a similar manner to the creative act of 'giving form to the unseen' (Leach, 1988: 7). At work here is a new type of imagination 
(phantasia), the type Aristotle stumbled upon in his treatise on the human soul De Anima that behaves 'like sensation but without the actuality of the effective presence of the object' (Castoriadis, 1994: 197). ${ }^{13}$ This kind of imagination carries a lot more mass than the vapors of self-referential metaphysical arabesques and abstractions. Directed by material reality, it proceeds by fabricating effigies of life, giving a surrogate form and figure to things that are not accessible as such. As we will see, Weber's famous ideal-types are in essence such effigies of actuality at work.

\section{Phantasia, Imagination, and Actuality}

'There is no such a thing as a purely observational science' wrote Karl Popper, adding: 'there are only sciences in which we theorize (more or less consciously and critically)'. Another way of thinking about this, as Popper puts it, is that 'theory-free descriptions do not exist' (1976: 101). This holds for both social and natural sciences.

Scientific perception, in essence, is an ever extended and augmented act of witnessing through various surrogate frameworks and proxy devices. This is what the experimental set up is at its core. That means: an experiment attempts to generate a controlled event which can be witnessed. The more complicated the problem, the less direct such a witnessing is, relying on mediated realties and the extension of the senses (think the proverbial telescope/microscope in natural sciences or the aggregate statistic in sociology to capture the reality of a mass society). In other words, the act of rigorous observation is an act of more or less direct witnessing, with an entire set of procedures to approximate it. By extension, the question for sociology as it grew in scope, to which the currently perceived crisis of method (Savage and Burrows, 2007, 2009) is intimately connected, became 'how do we witness life as directly as possible in its many, overlapping 
spatial and temporal dimensions'? The implication here is that we cannot witness the social element in its complexity and nuance without also paying attention to the temporal structures that underpin it. Using temporal frames to isolate a fragment of social life is the closest thing we have to an experimental environment, where what is chosen and how it is put together into various types of interaction can in some measure be controlled. One well known classical precursor to this kind of temporal framing, often misunderstood as exclusively a heuristic device, are Weber's as ideal-types - and I would like to reconsider them briefly.

Ideal-types redraw the pathways of interaction and significance of what are deemed the essential elements of a particular context. They work on making the implicit explicit, where a particular phenomenon or 'experience when it is made into an object, acquires perspectives and interrelationship which were not "known" in the experience as such" (Weber, 1949 [1905]: 178). In order to enliven reality through these newly 'found' perspectives, one needs to establish and maintain a strange type of contact with what is not accessible which combines old with the new, setting up, as much as possible, a series of encounters that trigger the emergence of reconfigured images of life under specific material conditions. This is why any model based on an ideal-types

is a conceptual construct (Gedankenbild) [thought-image] which is neither historical reality nor even the 'true' reality [Wirklichkeit] ... It has the significance of a purely limiting ideal concept [Grenzbegriff], or boundary-concept] with which real situation or action is compared ... By means of this category, the adequacy of our imagination [Phantasie], oriented and disciplined by reality, is judged (Weber, 1949 [1904]: 93)

Following Goethe's dictum that 'everything factual is already theory' (1998: 77) Weber's modeling of life based on amplification of implicit relationships that work through 
a specific social-historical constellation depends on the kind of imagination that makes 'social facts' appear. Such orientation

involves first the production of - let us say this calmly - imaginative constructs [Phantasiebildern or imaginary pictures] by disregarding of one or more of those elements of "reality" which [were] actually present, and by the mental construction of a course of events which is altered through modification in one or more "conditions" ... Even this first step thus transforms the given "reality" into a "mental construct" [Gedankengebilde thought-images] in order to make it into a historical fact (Weber, 1949 [1905]: 173).

This is the only way to gain interpretive access and grow understanding. This kind of imagination is not pure fancy but a condensed extension of the empirical based on certain evident qualities of the fragment of a past under scrutiny. Hence, 'an "understanding" of human behavior that has been obtained by means of interpretation first of all possesses a specific qualitative “evidentness” [Evidend] whose strength may vary considerably' (Weber, 2012 [1913]: 273). The intensity of that evident-quality depends on what type of experience is being investigated from what sort of scientific perspective or paradigm, and it is our responsibility as well attuned witnesses of life to keep designing methods that can intensify the presence of such 'evidentness' derived from the context under scrutiny. And words matter here. 'Evident' and its derivatives based on evidentia (clarity/vividness) is a direct translation of enargeia into Latin. ${ }^{14}$ In fact, what we have stumbled upon in Weber is a modeling of life and its understanding based on the principles of vividness/enargeia. This style of thinking becomes quite unmistakable once we take stock of Weber's overall project; the definition of his science as a type of carefully calibrated/valid rendition of experienced life (the hallmark of 'enargeic' or vivid presentation); his persistent attempt to render actuality evident in its implicit character, and as we will see below, unflinching admission of imagination (Phantasie) as the condition sin qua non of his 'science of 
actuality' (Wirklichkeitswissenschaft). Thus, the kind of imagination through the active past I am attempting to recover and reinstate, the one also deployed by Weber, is an imagination that furnishes a more accurate and finely calibrated access to reality, broadly speaking.

A specific type of imagination as phantasia is indispensable to the science of actuality based on ideal-types, because

It is a matter here of constructing relationships which our imagination [Phantasie] accepts as plausibly motivated and hence as 'objectively possible' and which appear as adequate from the nomological standpoint (Weber, 1949 [1904]: 91-92).

Ideal-types create perceptive spaces that render things (to the extent that this is possible) clear, visible, and distinct. Again, in a manner similar to the enlivened dimension opened up by the technique of enargeia, ideal-types are 'neither empirical reality nor reproductions of it' (Weber, 1949 [1904]: 111]). Rather, they are trans-dimensional frames that let phenomena emerge in a valid manner as Weber says, which means, they take direction from life, amplifying what are the essential components of actuality in its particular historical shape. In other words, we are facing here a specific type of emergence, which, following in the footsteps of enargeia, evokes a sense of what is technically speaking absent. Of course, an approach 'that compels ... [cultural] sciences to a continual refinement of concepts [which in turn will] constantly approximate the invariably individual, actual reality' as they attempt to find life's foot-prints in an immediately and clearly evident focus' (Weber, 2012 [1904]: 6) is in itself an ideal-type of a method that must be continually reassessed and adjusted accordingly. But the core of this analytical engagement is still based on the constantly renewed construction of bespoke temporal complexes that define limits at which observation takes place. Placed at the threshold of where immediate experience/perception of life (Erleben) lies adjacent to the type of experience extracted 
from it (Erfahrung), the validity and relevance of our models of actuality can only be derived through an analytical orientation that knows how to reanimate a certain sense of lost, or not immediately present, experience. This type of mobilization of the analytical perception relies on a particular thought-image (Gedankenbild) or even more accurately a thought-display/exhibit where

Even one's own "experience" as soon as it becomes an object of thought, cannot simply be "depicted" or "replicated" ... instead it would constitute a renewed immediate experiencing of the former "immediate experience", or rather - as that is impossible - a new immediate experience that involves the feeling ... of having once already "immediately experienced" this - this being part which remains indeterminate ... (Weber, 2012 [1904]: 71)

The indeterminate quality or experience that is being renewed finds fulfillment only in the moment of evocation which 'does not dissolve it but enlarges it, gives it amplitude and a density, and a vibration or an undulation whose outline never does anything but approach' (Nancy, 2007: 2). This is how mere listeners become spectators/witnesses, mere readers hear the voices from the past, and mere onlookers become affective agents.

\section{Conclusion: Vivid Frames}

'Time itself seems exhausted' writes Nina Power (2012), attempting to capture a sense of temporal pessimism striking at the heart of modern life. Whether it is in the form of a traumatic past, a hopeless future, or the sleepless present, culturally, socially and politically the temporal anchors have been set adrift. Duration as a weapon (Power talks about the 'weaponisation of time) or as a risk management technique (think financial markets for instance, and investment in the so-called Futures), is in a frantic, hyper-vigilant state. And sociology cannot ignore it any longer - time must be reinstated as an active element of sociological method. 
By engaging temporality as an analytical force through the technique of enargeia, as well as by setting out a diagnostic picture of the current temporal environment in operation, this paper was meant to serve as a starting point for a larger reassessment of sociological imagination and inquiry. As a debating piece, it leaves some questions unanswered, but there are two general proscriptions relating to the injection of time into our analytical frameworks, that can be suggested.

\section{1) Make time vivid by forgetting chronology as the defining element}

The first step here is to get away from the impulse of simply equating duration with history that divides temporality as a matter of principle into expired/dead time (historical past) and current time. History, as we understand it, has traditionally defined the past as anything that does not 'belong to the power of producing a present' (de Certeau, 1986: 216) in its immediate form. It is only by freeing ourselves from such standardized relationship to time, that we might be able to inhabit the many gaps in presence - the gaps where research ultimately happens. Enargeia/vividness lives in these perceptive gaps. In contrast, chronology, or duration 'recast in the mold of a taxonomic ordering of things ... becomes the alibi of time, a way of making use of time without reflecting on it' (de Certeau, 1986: 216). Chronology is anything but a natural phenomenon. It is different from the psychological sense of succession, the feeling and the rhythm of before and after, which are elastic, irregular phenomena. In contrast, chronology is an external framework that at one point 'in its merger with history ... has become a social technology' (Tanaka, 2016: 164).

It is only such a disavowal of chronology that ties duration to linear trajectories (even if these are multiple and uneven) that allows for the reinsertion of the past into the present culturally (this is how duration is lived) but especially analytically. One useful and 
effective approach to this reopening of sociological imagination via the past can be found through the history of concepts that underpin contemporary social understanding of life. Take, for instance, the notion of crisis (Koselleck, 2006). From it, we learn that the term does not simply denote an emergency or an alarming situation, especially in relation to economics (the most common application of crisis today), but is underpinned by an entire assemblage of definitions, meanings, perceptions, and perspectives, which make up its historical life-course. In German lexicography, for instance, the concept was formally used in relation to economics only in 1931 (Koselleck, 2006: 367). Even though this application concluded a developmental circuit that makes crisis something like a 'structural signature of modernity' (Kosseleck, 2006: 372), it is the fact that previously all transitions were in some sense crisis driven, intimately involved in 'situations reaching a decisive point [marking] fundamental changes in constitutions in which the alternatives were the survival or demise of a political entity' (369), the human body (crisis was used in medicine for the longest time), delivery of justice (it was a legal principle), and theology (the notion of final judgment), that is especially useful analytically for us, today. The medical use of crisis, which happens to be the longest uninterrupted application of the concept going back some fifteen hundred years (Kosseleck, 2006: 360), fuses direct observation and judgment about the course of an illness into one, thus releasing a type of diagnostic temporality which then determines the course of treatment. All crises, whether ecological, economic, political, or personal, carry this multifaceted, encoded past within their contemporary constitution. By amplifying these, discerning which of them are more or less evident, how their interaction with contemporary social realities refracts the normalized surface of life, and what arises from such a collision of temporalities encoded into various linguistic and material formations, that we enliven the data that emerges from the weave of the temporal fabric. 
This is exactly what Weber's ideal types were: i.e., a rigorously extracted past that could then be inserted into the contemporary context and used to interpret the present. This means: the conceptual and empirical profile of a phenomenon with the entire weight of a 'historical' underpinning (think the 'Protestant ethic' or the 'charismatic personality') would be transplanted to the contemporary setting, like a skin graft. It is a non-linear, unbound temporality that releases a kind of 'roaming sociological imagination ... willing to mutate sociology' (Puwar \& Sharma, 2012: 57) and open up new dimensions and analytical windows onto the present.

\section{2) Let Time Intervene not simply Interpret}

Escaping the dictatorship of chronology frees temporality to circulate actively through the present. It is a time lived culturally in many forms and dimensions, as nostalgia, memory, heritage, trauma, biography. As heterogeneous temporality, it is underpinned by multiple and concurrent forms of passing that we need to follow and weave into data by bestowing 'the dignity of the unknown upon the well-known' (Arendt. 2004: 222, quoting Novalis). In this sense duration sheds its exclusive, monocular identity as an interpretive framework (standard, chronology driven history), and becomes interventionist, and as such vivid/enargeic. Can we find any contemporary instances of research that embody this principle of vividness? One interesting example is the Noise of the Past project (Puwar and Sharma, 2012). The project aimed to redirect and enliven the memory of war, especially the role of Britain's colonial soldiers in conflict.

How does one bring into presence a suppressed past that depends on the now absent and often undocumented events? This was done across several dimensions that fit the four spheres of vivid/enargeic reconstitution already proposed by Erasmus. These 
dimensions are: place (topographia), biography/people (prosopopeia), thing (hypotyposia) and of course underpinning all these, time (chronographia). Noises of the Past actively deployed all four. The place and the main theatre of operations for the project was the Coventry Cathedral - already a powerful symbol of war and commemoration, bombed out during the Battle of Britain, and reactivated as a site of memory by the composer Benjamin Britten when his War Requiem premiered there in 1962 . This was supplemented by a specific biography of Sawarn Singh, a colonial solider in Burma, the Middle East and Africa during WWII, whose life was 'thrown' into an intergenerational dialogue with, among others, his grandson. The interaction of place and, via Sawarn Singh's biography, as well as the artistic productions that followed (poetry in Urdu, and short film, and a musical composition) brought the thing, in this case a history of 'under-documented' war, vividly in front of the readers/spectators/listeners eyes in a surrogate form. In essence, a new 'theatre of operations' was created for a series of suppressed events, although Puwar and the team stop short of a fully conscious extension and elaboration of their results into a set of epistemological consequences, relying more on feel, contingency, and instinct in their approach. But a more systematic approach is there for the taking via the dynamics of enargeia which pays heed to the not readily visible, missing, yet implicitly felt, and then pumps them full of life. This type of 'enargeic' way of thinking is becoming more and more resonant in sociology, especially in areas that are difficult to access and capture analytically. For instance, Tarr et al (forthcoming) in the process of reflecting on their project that involved chronic pain sufferers, conclude:

Powerful live methods articles would seek to bring their phenomenon to life: to convey the immediacy of being there, the contingency of researchers' interpretations, and allow the reader to engage in a live interpretative interaction with the material. (31) 
These examples do not mean to indicate that the only way to recover the lived element in research is to design resource and labour intensive projects that physically manipulate various environments. Above and beyond all that, vivid imagination should come into play from the very beginning of research design, by cultivating the 'liveliness of words' (Back, 2012: 21), metaphors and events - what the humanists of past centuries, such as Erasmus, already advocated and understood well. The crucial issue of 'how to account for the social world without assassinating the life contained within it'? (Back, 2012: 21) is a matter of pushing the limits of what we deem worthy of analytical interest, by letting the past intervene in the present. Whilst intensifying and redirecting how we frame various types of phenomena via an active past used as a resource for understanding the present, we also augment the profile of what type of data can be collected and how it lends itself to observation. Such imagination cannot be generated without reactivating the most important and intense dimension of life and by extension vivid/live sociology - time. Only this analytically reactivated past, which is always at work behind the scenes in any case, has the power to chase all the extraordinary and out-of-reach phenomena by which we seem to be governed 'into the contours of the ordinary' (Alexievich, 2016: 29). 


\section{Notes}

${ }^{1}$ The Sociological Review devoted an entire special issue to this theme in 2012.

${ }^{2}$ In fact, all cultural memory takes the form of continually reactivated past.

${ }^{3}$ In fact, since the mid nineteenth century, the modern discipline of history has been instrumental in biding, congealing, and maintaining these foreclosed identities, most commonly known under the designation of a 'national history'.

${ }^{4}$ Whilst working on this paper, I have received an advert in my inbox from the online furniture shop MADE.com. The advert was offering to take me back to circa 1952, and the ambiance of its specific interior design (as seen in the recent Hollywood film Carol) which, as I'm being told 'can be copied affordably'. http://us1.campaign-archive1.com/? u=bb902ca9cd9e1e15c72c3984f\&id=0af791188b\&e=c573bc9309.

${ }^{5}$ A live archive of the sort proposed by the Library of Congress that aims to store and conserve every digital bit of information contradicts the traditional logic of archiving based on selectivity, gaps, and in essence forgetting as much as preserving. For a brief overview of the project and how it has stalled, see the recent article in Politico http://www.politico.com/storv/2015/07/librarv-of-congress-twitter-archive-1 19698.html

6 A condensed synopsis of the ruling can be found at http://ec.europa.eu/justice/dataprotection/files/factsheets/factsheet data_protection_en.pdf

${ }^{7}$ Such a past is most commonly known as heritage - in itself a recent invention. For instance, UNESCO world heritage convention, designating specific sites as protected, is only four decades old, established in 1972; English Heritage was created in 1983. For an excellent discussion of this theme see Hartog (2015), especially chapter 5 .

${ }^{8}$ It is not a coincidence that the Director of Antiquities at the Vatican circa 1573 bore the title of "Commissioner of Treasure and other Antiquities and of Mines" - see (Hartog, 2015: 162 - 170).

${ }^{9}$ Anthropology has been altogether much more sensitive and consistent in its engagement with the issues of time, history, and memory, especially in its local, ethnographic, and autobiographical renditions. A good thematic overview is provided by Birth (2006).

${ }^{10}$ These narratives of events were based on the transformation of eye witness accounts and their immediate vision (autopsy) into an image of the recent past or perhaps more accurately, the near present (see Cassin, 2014: 439 - 450).

${ }^{11}$ For the use of enargeia in ancient philosophy as the criterion of truth see Morision and Ierodiakonou (2011).

${ }^{12}$ In De Ratione Studii, Erasmus writes: "All knowledge falls into one of two divisions: the knowledge of 'truths' and the knowledge of 'words' ... For ideas are only intelligible to us by means of words which describe them", (1904 [1511]: 162) and this is why, as he goes on to argue, words must be cultivated intensively.

${ }^{13}$ Phantasia is related to phainomai "to come to light, to appear", from which we also get 'phenomenon'. This kind of appearance can be external or internal but it is always anchored empirically, as we would say today, even though it can also constitute a false appearance. The sense of modern imagination as unmoored sense impression, or production of 'free' images based on the Latin root imaginare (to form a mental picture, imagine, represent to oneself), does not appear until the second century CE. The Roman scholar Quintilian 
in the first century CE used phantasia to describe a special kind of live image or vision (viso) triggered by an orator whose passion makes the listeners see vividly before their eyes the narrated scene, thus explicitly connecting imagination as phantasia, with the model of representation based on enargeia. For a detailed historical and etymological expose, see (Cassin, 2014: 772 - 777).

${ }^{14}$ We should note here that the use of rational action as a model for social behaviour is only privileged when and because it intensifies the evident-quality of the phenomenon under scrutiny: 'the fact that the purposively rational behavior possess a specific evidentness does not entail that rational interpretation should be regarded as a specific goal of sociological explanation' (Weber, 2012 [1913]: 274) - Talcott Parsons completely ignored this qualification in his influential rendition of Weber's sociology.

References

Abrams, P., (1982), Historical Sociology, Open House.

Adam, B., (1990), Time and Social Theory, Cambridge: Polity Press.

Adam, B., (1995), Time Watch: The Social Analysis of Time, Cambridge: Polity Press.

Adkins L. and Lury, C., (2009), 'What is the Empirical?', European Journal of Social Theory 12 (1): 5-20.

Alexievich, S., (2016), Second-Hand Time, London: Fitzcarraldo Editions.

Arendt, H., (2004), The Origins of Totalitarianism, New York: Schocken Books.

Benjamin, W., (1968), 'Theses on the Philosophy of History', in Arendt H. and Zohn H., (eds) Illuminations New York: Schocken Books, 253-264.

Back, L. and Puwar, N., (2012), (eds) Live Methods. Oxford: Wiley-Blackwell/The Sociological Review.

Back, L., (2012), 'Live Sociology: Social Research and Its Futures', The Sociological Review 60 (1): 1839.

Birth, K., (2006), 'The Immanent Past: Culture and Psyche at the Juncture of Memory and History', Ethos 34(2): 169-91.

Cassin, B., (2014), (ed) Dictionary of Untranslatables - A Philosophical Lexicon, Princeton: Princeton University Press.

Castoriadis C., (1994), 'The Discovery of the Imagination', Constellations 1 (2): 183-213.

Certeau., de M., (1986), Heterologies: Discourse on the Other, Minneapolis: University of Minnesota Press.

Clemens, E., (2007), 'Toward a Historicized Sociology: Theorizing Events, Processes, and Emergence', The Annual Review of Sociology 33: 527-49.

Connerton, P., (1989), How Societies Remember, Cambridge: Cambridge University Press.

Erasmus, D., (2012 [1513]), On Copia of Words and Ideas, King D.B. and Rix D.H., Milwaukee, Wisconsin: Marquette University Press. 
Erasmus, D., (1904 [1511]) 'De Ratione Studii', in Woodward W.H., Desiderius Erasmus Concerning the Aim and Method of Eduction, London: Cambridge University Press, 162-178.

Goethe, J.W., (1998), Maxims and Reflections, London: Penguin Books.

Ginsburg, K., (2012), Threads and Traces: True False Fictive, Berkeley, California: University of California Press.

Hartog, F., (2015), Regimes of Historicity: Presentism and Experiences of Time, New York: Colombia University Press.

Huyssen, A., (2003), Present Pasts: Urban Palimpsets and the Politics of Memory, Stanford, California: Stanford University Press.

Iglis, D., (2014,) 'What is Worth Defending in Sociology Today? Presentism, Historical Vision and the Uses of Sociology',Cultural Sociology 8 (1): 99-118.

Koselleck, R., (2006), 'Crisis', Journal of the History of Ideas, 67 (2): 357-400.

Leach, E., (1988), The Rhetoric of Space: Literary and Artistic Representations of Landscape in Republican Augustan Rome, Princeton: Princeton University Press.

Mills, C.W., (2000 [1959]), The Sociological Imagination, Oxford: Oxford University Press.

Nancy, J.L., (2007), Listening; New York: Fordham University Press.

Nietzsche, F., (1997 [1873]), 'On the Uses and Abuses of History for Life', in Breazeale D. (ed), Untimely Meditations, London: Cambridge University Press, 57-123.

Morison, B. and Ierodiakonou K., (2011), 'The Notion of Enargeia in Hellenistic Philosophy', Oxford Scholarship Online: 1-16.

Plett, H., (2012), Enargeia in Classical Antiquity and the Early Modern Age: The Aesthetics of Evidence, Leiden: Brill.

Popper, K., (1976), 'The Logic of Social Sciences', in Adey G., and Frisby D., (eds) The Positivist Dispute in German Sociology, London: Heinemann: 87-104.

Power, N., (2012) 'The Pessimism of Time', Overland 209, Summer (https://overland.org.au/previousissues/issue-209/feature-nina-power/), accessed 27/06/16.

Puwar, N. and Sharma, S., (2012), 'Curating Sociology', in: Back L. and Puwar N., (eds), Live Methods. Oxford: Wiley-Blackwell/The Sociological Review.

Rabinow, P., (2008), Marking Time: On the Anthropology of the Contemporary, Princeton: Princeton University Press.

Reynolds, S., (2011), Retromania: Pop Culture's Addiciton to Its Own Past, London: Faber and Faber.

Savage, M., (2013), 'The "Social Life of Methods”: A Critical Introduction', Theory, Culture \& Society 30 (4): 3-21.

Savage, M. and Burrows R., (2007), 'The Coming Crisis of Empirical Sociology', Sociology 41 (5): 885-899.

Savage, M. and Burrows R., (2009), 'Some Further Reflections on the Coming Crisis of Empirical Sociology', 
Sociology 43 (4): $762-772$.

Sewell, W. H. Jr., (2005), Logics of History: Social Theory and Social Transformation, Chicago: Chicago University Press.

Sharpling, G.P., (2002), 'Towards a Rhetoric of Experience: the Role of Enargeia in the Essays of Montaigne' International Society for the History of Rhetoric 20 (2): 173-192.

Tanaka, S., (2015), 'History without Chronology', Public Culture, 28 (1): 161-185.

Tarr, J., et al (forthcoming). 'On Liveness: Using Arts Workshops as a Research Method', Qualitative Research.

Uprichard, E., (2012), 'Being stuck in (live) time: The Sticky Sociological Imagination', in Back L. and Puwar N., (eds) Live Sociology, Oxford: Wiley-Blackwell/The Sociological Review: 124-138.

Weber, M., (2012 [1904]), 'Roscher and Knies and the Logical Problems of historical Economics', in Bruun H.H. (trans) Max Weber Collected Methodological Writings, London: Routledge: 3-93.

Weber, M., (2012 [1913]), 'On Some Categories of Interpretive Sociology', in Brunn H.H. (trans) Max Weber Collected Methodological Writings, London: Routledge: 273-301.

Weber, M., (1949 [1904]), 'Objectivity in Social Science and Social and Social Policy', in Shils, E.A. and Finch, H.A. (eds) The Methodology of the Social Sciences. New York: The Free Press: 49-112.

Weber, M., (1949 [1905]), 'Critical Studies in the logic of the Cultural Sciences', in Shils, E.A. and Finch, H.A. (eds) The Methodology of the Social Sciences. New York: The Free Press: 113-188.

Zanker, G., (1981), 'Enargeia in the Ancient Criticism of Poetry', Rheinishes Museum für Philologie 124: 297-311. 